\title{
Design Analysis of 110kV Double Circuit Narrow-Base Steel Pipe Tower
}

\author{
Ye Xin ${ }^{1}$, Yinhe Lin ${ }^{1}$, Jingfeng $\mathrm{Guo}^{1}$, Xiaoxu Fu${ }^{1}$ and Ming Xie ${ }^{1}$ \\ ${ }^{1}$ Fujian Yongfu Power Engineering Co., Ltd, Fuzhou, Fujian Province, 350000, China
}

\begin{abstract}
Secondary bending moment and geometric nonlinearity should be taken into account in pipe tower design. Taking the $110 \mathrm{kV}$ double-circuit narrow-base steel pipe tower as an example, the $110 \mathrm{kV}$ double-circuit narrow-base steel pipe tower is compared and analyzed through the tower structure design software and the general finite element software ANSYS. The analysis results show that the narrow-base steel tube tower should adopt a rigid-truss structure model, and the influence of the secondary bending moment of the main material and the geometric nonlinearity should be considered. The secondary bending moment effect accounts for about $10-20 \%$ of the strength stress of the steel pipe main material. Through comparative analysis, a number of design points are summarized, which provides a certain practical guiding significance for the design and application of the double-circuit narrow-base steel pipe tower.
\end{abstract}

\section{Introduction}

With the continuous development of Chinese power grid construction, the line corridors have become more and more narrow. Especially, the suburban line corridors are becoming more and more precious. The narrow-base steel pipe tower has beautiful appearance, good structural performance and small line corridors. It has high social and economic benefits in suburbs and tight line corridors. It is more and more favored by the power supply department. However, China's "Technical Regulations on Steel Pipe Tower Design for Overhead Transmission Lines"[1] does not specify the strength reduction method and design method of steel pipe truss members under secondary stress. At the same time, the current Chinese tower structure design software TTA, Daoheng and other software all use truss models Computational theory. A large number of tests have shown that the use of truss structure model is very consistent with the angle steel tower with smaller member stiffness and larger length and slenderness. However, the foundation of the narrow-base steel pipe tower is small, the structure is relatively flexible. The main material is large and the length of the steel pipe member is small.The rigidity of the main material member is large. The use of the truss calculation model makes the structural analysis result unable to truly reflect the actual force of the structure[2].

Therefore, by establishing a finite element calculation model, it is very necessary to analyze the influence of structural geometric nonlinearity and secondary bending moments on the structure of the narrow-base tower[3].

\section{Calculation model and method of narrow base steel pipe tower}

At present, the calculation model of ordinary tower mainly adopts the truss model, and its rationality has been proved in experiments and theoretical analysis. The main material of the narrow-base steel pipe tower is steel pipe and its two ends are connected by flanges, which can not only bear the axial force. It also bears the shear force and bending moment. However, the angle steel is used for the oblique material of the tower body, which has less rigidity and fewer fixing bolts at both ends, and its connection method is more inclined to the hinged rod. Therefore, the main material of the calculation model of the narrow-base steel tube tower structure in this paper adopts beam elements and the oblique material adopts truss elements. So a rigid-truss combination model is established[4].

The main material of steel pipe adopts beam element, considering the effect of bending moment, the actual force of the main material of steel pipe tower is tension bending or compression bending. The calculation needs to consider the influence of axial force and bending moment on the force of the members at the same time[5]. According to the steel structure design standard, the influence degree of the secondary bending moment on the strength and stability calculation is considered.

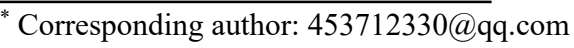




\section{Analysis of the influence of the secondary bending moment of the narrow-base steel tube tower}

This paper takes $110 \mathrm{kV}$ double-circuit narrow-base steel pipe tower as an example. The design conditions of the tower are: the tower height is $38.6 \mathrm{~m}$ and the root opening is $2.5 \mathrm{~m}$ while the design wind speed is $29 \mathrm{~m} / \mathrm{s}$. The finite element model is shown in Figure 1. The main material of the steel pipe is simulated by Beam 4 element and the oblique material is simulated by Link8 element. The ANSYS general finite element is used for analysis. The calculation results are shown in Table 1 and Table 2.

Table 1 Analysis of main member of pipe tower

\begin{tabular}{|c|c|c|c|c|c|c|c|c|c|c|c|c|}
\hline \multirow{2}{*}{$\begin{array}{l}\text { Section } \\
\text { number }\end{array}$} & \multirow{2}{*}{ Type } & $\mathrm{N} 1$ & $\begin{array}{c}\text { Strength } \\
\text { stress } \sigma_{1}\end{array}$ & $\begin{array}{c}\text { Stable } \\
\text { stress } \sigma_{1}\end{array}$ & $\mathrm{~N} 2$ & $\mathrm{My}$ & $\mathrm{Mz}$ & $\begin{array}{c}\text { Strength } \\
\text { stress } \sigma_{3}\end{array}$ & $\begin{array}{c}\text { Stable } \\
\text { stress } \sigma_{4}\end{array}$ & $N_{2} / N_{1}$ & $\frac{\sigma_{1}}{\sigma_{3}}$ & $\frac{\sigma_{2}}{\sigma_{4}}$ \\
\hline 1 & $\Phi 140 \mathrm{x} 5 \mathrm{H}$ & 33.5 & 222 & 105 & 221 & 0.7 & 0.3 & 114 & 122 & $99.4 \%$ & $116.8 \%$ & $104.7 \%$ \\
\hline 2 & $\Phi 159 \times 6 \mathrm{H}$ & 33.3 & 774 & 268 & 770 & 2.3 & 0.7 & 290 & 317 & $99.5 \%$ & $118.2 \%$ & $106.1 \%$ \\
\hline 3 & $\Phi 273 \times 7 \mathrm{H}$ & 27.6 & 1533 & 262 & 1501 & 17.1 & 1.7 & 296 & 302 & $98 \%$ & $115.1 \%$ & $106.3 \%$ \\
\hline 4 & $\Phi 325 \times 8 \mathrm{D}$ & 23.3 & 2493 & 313 & 2441 & 33 & 3.3 & 353 & 358 & $97.8 \%$ & $114.5 \%$ & $106.7 \%$ \\
\hline 5 & $\Phi 356 \times 12 \mathrm{D}$ & 24.7 & 3775 & 291 & 3723 & 20.6 & -5.7 & 304 & 328 & $98.6 \%$ & $112.6 \%$ & $104.1 \%$ \\
\hline 6 & $\Phi 377 \times 14 \mathrm{D}$ & 23.4 & 5130 & 321 & 5065 & 33.2 & -5.3 & 338 & 362 & $98.7 \%$ & $112.7 \%$ & $105.0 \%$ \\
\hline
\end{tabular}

Note; axial force unit: kN; My, Mz: kN.m; stress unit: N/mm²

Table 2. Analysis of other members of pipe tower

\begin{tabular}{|c|c|c|c|c|}
\hline \multirow{2}{*}{ No. } & \multirow{2}{*}{ Type } & \multicolumn{2}{|c|}{ Axial force } & \multirow{2}{*}{ Radio } \\
\cline { 3 - 4 } & & Truss model & Beam model & \\
\hline 7 & L75x 6H & 82.72 & 83.81 & $101 \%$ \\
\hline 8 & L110x 7H & 117.96 & 128.94 & $109 \%$ \\
\hline 9 & L110x 8H & 144 & 165.07 & $115 \%$ \\
\hline 10 & L90x 6H & 36.32 & 56.22 & $155 \%$ \\
\hline 11 & L90x 6H & 39.76 & 55.64 & $140 \%$ \\
\hline 12 & L125x 8H & 113.01 & 127.01 & $112 \%$ \\
\hline
\end{tabular}

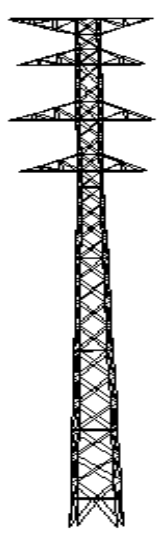

Fig. 1. Finite element model of tower

It can be seen from the data comparison in Table 1 2:

1) Compared with the rigid-truss hybrid model and the truss model, the axial force of the main steel pipe material is reduced by about $2 \%$, but considering the effect of the secondary bending moment of the main material of the tower body, the strength and stress of the rigid-truss model is about $12 \%-20 \%$ than that of the truss model. The stable stress is $6 \% \sim 12 \%$ larger than that of the truss model.

2) The rigid-truss hybrid model is compared with the truss model. In the rigid-truss hybrid model, the internal force of the oblique material is larger, especially the diaphragm material increases. It is recommended to use the rigid-truss hybrid model to check the oblique material in the design.

\section{Geometric Nonlinear Analysis of Narrow-Base Steel Pipe Tower}

The narrow-base steel tube tower has a very large ratio of height to root opening and its structure is more flexible while its geometric nonlinearity is more affected than conventional towers. The structure mainly undergoes overall bending deformation under the design load and its failure type belongs to the extreme type instability. The following uses linear and geometric nonlinearity to compare the displacement and internal force of the narrow-base steel tube tower.

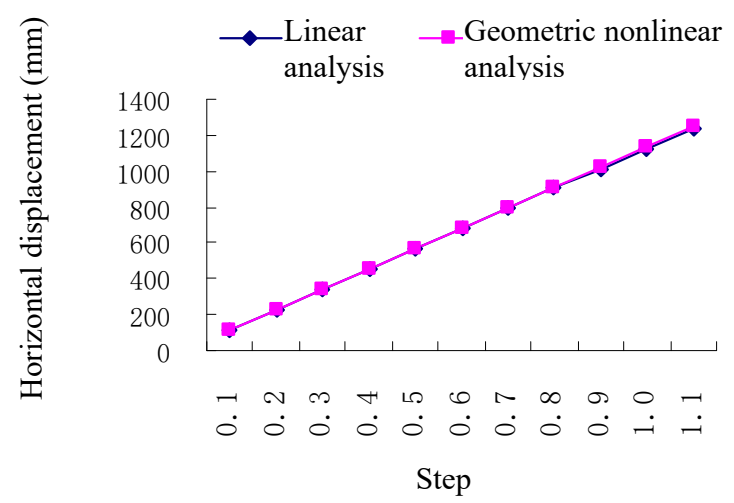

Fig. 2. Changes in the horizontal displacement of the apex of the tower body with loading 


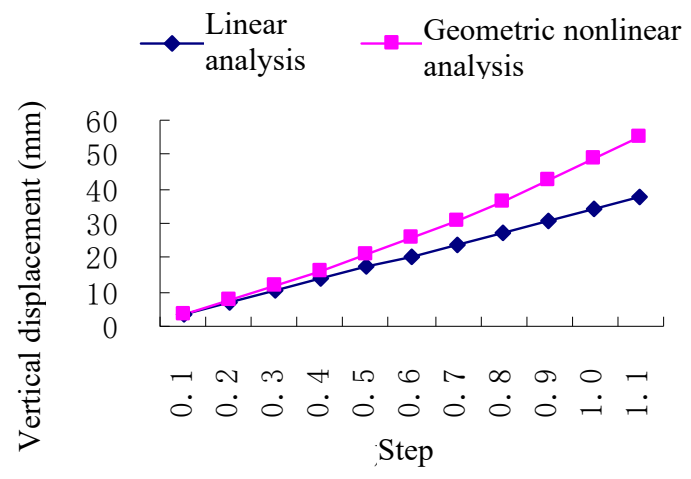

Fig. 3. The vertical displacement of the apex of the tower body changes with the load

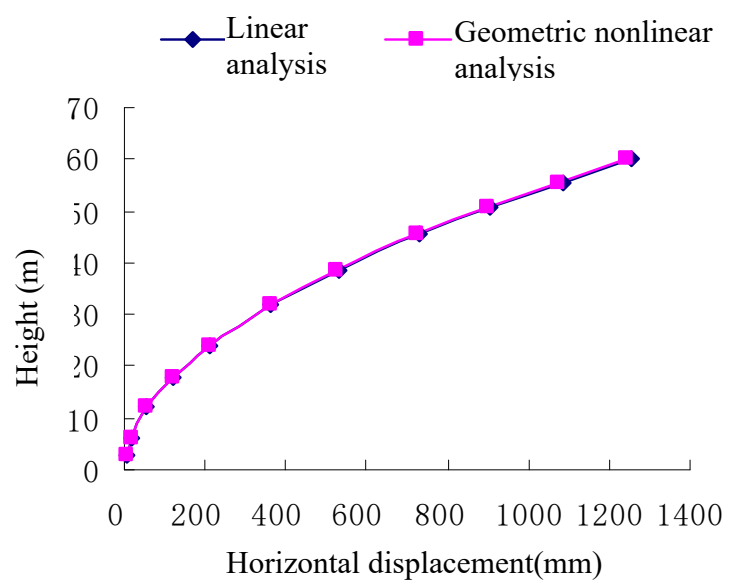

Fig. 4. Horizontal displacement of towers at different heights

It can be seen from Fig. 2 that the horizontal displacement of the narrow-base steel pipe tower changes linearly with the load and the calculation results of the two analysis methods have little deviation; Fig. 3 shows that the vertical displacement of the narrow-base steel pipe tower increases with the load of the two methods. It can be seen from Fig 4 that the narrow-base steel pipe tower is mainly bent and deformed as a whole.

Through the force analysis, it is concluded that the geometric nonlinearity has less than $1 \%$ influence on the internal force of the main material of the narrow-base steel tube tower, but the geometric nonlinearity has a greater influence on the inclined material of the narrowbase steel tube tower and some other members are $50 \sim 70 \%$ larger than the linear analysis.

\section{Detail design}

1) In principle, eccentricity is not considered for the node connecting the branch pipe and the main pipe, but for the components with little force (such as auxiliary materials, etc.), it can be designed as a non-eccentric connection, as shown in the figure below:

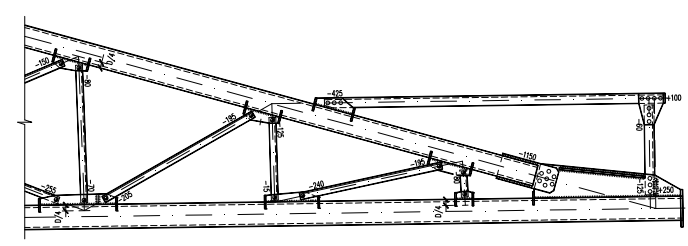

Fig. 5. Non-eccentric connection

2) When the circumferential butt weld of steel pipe crosses the longitudinal connecting plate of the steel pipe, the circumferential weld shall be ensured to pass through.aWhen the circumferential stiffening plate weld of the steel pipe intersects the longitudinal connecting plate of the steel pipe, the penetration of the weld of the longitudinal connecting plate shall be ensured to avoid welding. The stitches are superimposed on each other.
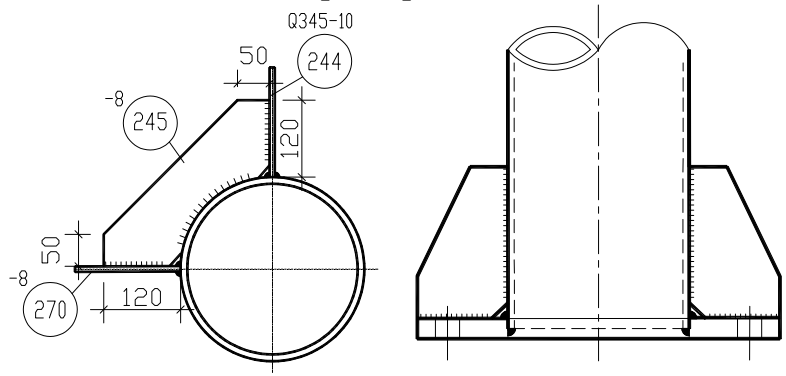

Fig. 6.Non-eccentric connection

3) The length of the steel pipe should not exceed 12 meters, and it should not be greater than 9 meters for high and low-leg towers; the weight of a single component generally does not exceed 5 tons and it should not be greater than 3.5 tons for high-low-leg towers. The open section of the cross arm should not exceed 3 sections and the weight of a single section should not be greater than 5 tons. The layout of the open break point of the cross arm should ensure that the installed section is a stable structure.

4) The connecting plates and construction holes used in the construction of the steel pipe tower should be actively requested from the design unit.

5) The location where zinc is easy to accumulate should be provided with galvanizing process holes. The diameter of which is $\Phi 13.5 \mathrm{~mm}$ or $\Phi 17.5 \mathrm{~mm}$ and it is better not to touch the welding seam. Water accumulation should be avoided at all welding points, otherwise $\Phi 13.5 \mathrm{~mm}$ drainage holes should be provided.

6) The main pipe of the bottom leg of the tower should be equipped with a water-shielding plate, as shown in the figure below. 


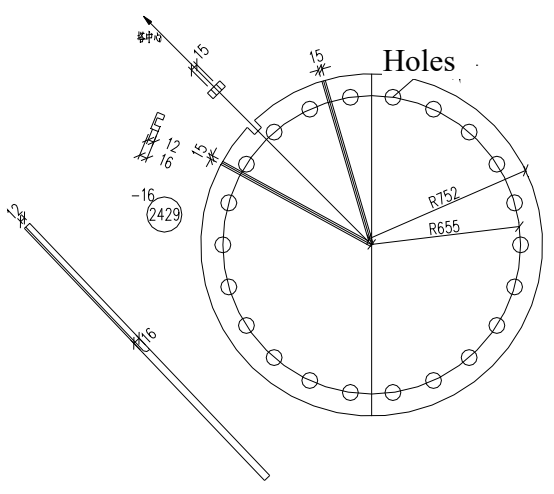

Fig. 7. Water-shielding plate

7) The step bolts on the main member are arranged staggered and the distance between the roots of the two step bolts in the horizontal direction is preferably $400 \mathrm{~mm}$. The left and right sides of the pipe diameter less than $400 \mathrm{~mm}$ are arranged staggered, as shown in the following figure.

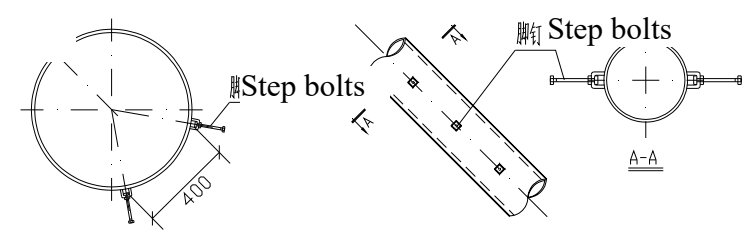

Fig. 8. Step bolts arrangement

8) Socket processing: When the pipe head type of the steel pipe component is T, U, UT, the instability of the plug-in plate can be ignored and it can be calculated according to the guaranteed net section tension and compression strength. It is recommended that the steel pipe tower web or diagonal joint type should be prioritized Optional. The I-shaped plug-in plate (that is, the veneer without stiffening ribs) is easy to buckle before the pipe fittings. It is recommended that the I-shaped board is not used for connection of small slenderness ratio pipes. The bearing capacity of the rod of the type pipe head can also meet the design requirements, but it is necessary to strictly calculate the size of the insert plate to prevent the insert plate from bending and breaking before the rod. The plugin plate of the pipe head of the steel pipe component should have a certain strength and rigidity and the thickness of the plug-in plate should not be less than the thickness of the steel pipe.

9) The load-bearing capacity of the steel pipe members is the highest when the U-shaped and UT-shaped pipe heads are used. This is because the U-shaped and UT-shaped connecting specimens have no structural eccentricity. Moreover, the connecting bolts of the U-shaped and UT-shaped pipe head components are double-shear and the number of connecting bolts can be reduced. But the processing and installation of the two are relatively complicated. If they are not handled properly, their bearing capacity may be small. The bearing capacity of Ttype and [-type pipe head components is second, and the structure is simple, and the processing and installation are more convenient. The I-type pipe head component has the smallest bearing capacity. Therefore, in the structural design, it is recommended to use U-shaped, UT-shaped or Tshaped pipe heads for the small slenderness ratio cross-inclined material connected by the plug-in board. The first two kinds of bolts are less in number, and the latter is more convenient for processing and installation. Time can be determined according to structural requirements. When the internal force of the component is not large, the [type pipe head can be used and the I-type pipe head should not be used as far as possible.

\section{Conclusion}

This paper takes $110 \mathrm{kV}$ double-circuit narrow-base steel pipe tower as the research object and establishes a finite element calculation model through ANSYS for analysis. It is very necessary to analyze the influence of structural geometric nonlinearity and secondary bending moments on the structure of the narrow-base tower. The conclusions are as follows:

1) The narrow-base steel pipe tower adopts the rigid frame-truss combination model and the calculation result of the axial force of the main steel pipe is about $1 \%$ smaller than that of the truss model, while the internal force of the oblique material is larger than that of the truss model (locally even 40-50\%);

2) The narrow base steel pipe tower is restricted by the root opening and the main steel pipe has a relatively small length and diameter. The secondary bending moment of the steel pipe main material has obvious influence. The secondary bending moment effect accounts for about $10-20 \%$ of the strength stress of the steel pipe main material and the secondary bending moment effect accounts for the steel pipe. The stable stress of the main material is about $5-12 \%$.

3) The geometric nonlinearity of the narrow-base steel pipe tower has little effect on the structure of the pole tower. The influence on the internal force of the steel pipe main material is less than $1 \%$, but the internal force of the inclined material of the pole tower is $5-10 \%$ and the partial diaphragm material reaches $40 \%$.

4) Because of the rigidity of the main material section of the narrow-base steel pipe tower, the overall structure is relatively flexible. It is recommended to use the rigidtruss combination model for geometric nonlinear force analysis.

5) In the detailed design stage, targeted optimization design should be carried out according to the characteristics of the narrow-base steel pipe tower.

\section{References}

1. Technical Regulations for the Design of Steel Pipe Towers for Overhead Transmission Lines: DL/T 5254-2010. China Construction Industry Press, 2010. 
2. Xing Hu, Yongzhong Bao. Analysis of Calculation Model of Transmission Tower. Electric Power Construction, Vol.31, No.12Dec, 2010: 33-37.

3. Jingbo Yang, Junke Han. Selection of Calculation Models for Steel Pipe Towers of UHV Transmission Lines. Electric Power Construction, Vol.31, No.12 Dec,2010:33-37.

4. Jiangguo Ying, Yuan Wang, etc. Analysis of Secondary Bending Moment and Local Stability of Steel Tube Tower and Design Suggestions [J]. Special structure, Vol.27 No.5 Oct. 5, 2010: 39-42.

5. Steel Structure Design Code: GB 50017-2017. China Planning Press, 2017. 